\title{
In vitro and in vivo consequences of variant medium-chain acyl-CoA dehydrogenase genotypes
}

Catharina ML Touw ${ }^{1,2,3^{*}}$, G Peter A Smit ${ }^{1,3}$, Klary E Niezen-Koning ${ }^{2,3}$, Conny Bosgraaf-de Boer ${ }^{2,3}$, Albert Gerding ${ }^{2,3}$, Dirk-Jan Reijngoud ${ }^{2,3}$ and Terry GJ Derks ${ }^{1,3}$

\begin{abstract}
Background: Medium-chain acyl-CoA dehydrogenase (MCAD) deficiency is the most common inherited disorder of the mitochondrial fatty acid oxidation, caused by mutations in the ACADM gene. Since the introduction of neonatal screening for MCAD deficiency, a subgroup of newborns have been identified with variant ACADM genotypes that had never been identified before in clinically ascertained patients. In vitro residual MCAD enzyme activity has been found to facilitate risk-stratification. In this study we integrated results of in vitro (residual MCAD enzyme activities) and in vivo (clinical fasting tolerance tests, and phenylpropionic acid loading tests) tests in this subgroup of newborns, defining the consequences of variant ACADM genotypes.
\end{abstract}

Methods: Enzyme analyses were performed in leukocytes with: hexanoyl-CoA (C6-CoA) +/- butyryl-CoA (C4-CoA), and phenylpropionyl-CoA (PP-COA). In vitro studies were performed in 9 subjects with variant ACADM genotypes, in vivo functional tests in 6 of these subjects.

Results: Enzyme analyses with C6-COA, C6-COA + C4-CoA, and PP-CoA identified significantly higher residual MCAD enzyme activities in subjects with variant ACADM genotypes when compared to patients with classical ACADM genotypes.

After prolonged fasting (range 15-18.5 hours) no hypoglycaemia was observed. Increasing concentrations of free fatty acids indicated lipolysis, and ketone body concentrations were sufficient for blood glucose concentrations in 5 out of 6 subjects. Phenylpropionic acid loading clearly demonstrated in vivo residual MCAD enzyme activity in all studied subjects.

Conclusions: Subjects with variant ACADM genotypes and residual MCAD enzyme activities $>10 \%$ display residual MCAD enzyme activities in vitro and in vivo. Our findings support the hypothesis that the guidelines on maximal duration of fasting might be abandoned in subjects with residual MCAD enzyme activities $>10 \%$ under normal conditions. An emergency regimen and parental instructions remain necessary in all subjects with MCAD deficiency, regardless of residual MCAD enzyme activity.

Keywords: ACADM, Enzyme, Genotype, Fasting, Phenylpropionic acid

\footnotetext{
* Correspondence: n.touw@umcg.nl

${ }^{1}$ Section of Metabolic Diseases, Beatrix Children's Hospital, University of Groningen, University Medical Centre, Groningen, The Netherlands 2Laboratory of Metabolic Diseases, Department of Laboratory Medicine, University of Groningen, University Medical Centre, Groningen, The Netherlands

Full list of author information is available at the end of the article
} 


\section{Introduction}

Inherited disorders of mitochondrial fatty acid oxidation (mFAO) are a group of acute presenting, life-threatening disorders among which medium-chain acyl coenzyme A dehydrogenase (MCAD [E.C.1.3.99.3; OMIM 201450]) deficiency is the most common [1]. Worldwide, population neonatal bloodspot screening (NBS) programs have become available for the disorder.

Before the introduction of MCAD deficiency in NBS programs, patients presented clinically with symptoms associated with a life-threatening hypoketotic hypoglycaemia, such as seizures, coma or even sudden death. The c.985A $>\mathrm{G}$ missense mutation on the $A C A D M$ gene (gene encoding MCAD, OMIM 607008) was the most common mutation. Since the introduction in NBS programs, the spectrum of $A C A D M$ genotypes changed dramatically. Novel $A C A D M$ genotypes were identified in prospectively screened asymptomatic newborns (i.e. variant $A C A D M$ genotypes), of which the clinical consequences are currently unknown. In previous studies our group and others emphasized the importance of determination of residual MCAD enzyme activity, both for diagnostic and prognostic purposes [2,3]. However, studies integrating laboratory (in vitro) and clinical (in vivo) data are scarce [4].

Currently, a late evening meal is advised during the first two years of life for patients with MCAD deficiency, regardless of the ACADM genotype [2]. Based on in vitro data, the necessity to treat all subjects with MCAD deficiency similarly is debatable, in particular with regards to the advice on maximum duration of fasting [2]. However, in vivo fasting tolerance under controlled conditions has not been studied before in this group of subjects. It can be hypothesised that residual MCAD enzyme activities and clinical fasting tolerance tests reflect the in vitro and in vivo role of these variant $A C A D M$ genotypes. In order to enable personalized care after diagnosis, clinical fasting tolerance tests were performed in our centre in subjects with variant $A C A D M$ genotypes after informed consent of the parents. In this study, we integrated data on in vitro MCAD enzyme assays, and in vivo functional tests from 9 subjects with variant $A C A D M$ genotypes.

\section{Methods}

The Medical Ethical Committee of the University Medical Centre Groningen approved the study (METc 2011/ 133). Parents agreed on participation by written informed consent.

\section{Cohort}

In the Netherlands MCAD deficiency has been included in the national population NBS program since 2007. Free carnitine $(\mathrm{C} 0)$, octanoylcarnitine (C8:0), decanoylcarnitine
(C10:0), and the C8:0/C10:0 ratio are determined in dried blood spots obtained from newborns 72 to 168 hours after birth (www.rivm.nl). Clinical and laboratory follow-up is initiated within 24 hours in newborns in case of elevated C8:0 concentrations. During the pilot NBS program in 20032006 the cut-off concentration for C8:0 was $0.30 \mu \mathrm{mol} / 1$ [5]. Since 2007, the cut-off concentration for C8:0 has been $\geq$ $0.50 \mu \mathrm{mol} / \mathrm{l}$ [2]. Diagnosis of MCAD deficiency is made after abnormal NBS, based on persisting abnormal metabolite profiles, the presence of 2 mutations on the $A C A D M$ gene, and/or residual MCAD enzyme activity $<50 \%$ when measured with hexanoyl-CoA (C6-CoA) in leukocytes. Laboratory analysis is always performed in family members of a proband, including all siblings.

Subjects carrying 'variant $A C A D M$ genotypes', who were diagnosed at the Beatrix Children's Hospital, UMC Groningen, Groningen, The Netherlands between 20032011 were included in our cohort. A 'variant $A C A D M$ genotype' was defined as an $A C A D M$ genotype that had not been described before in clinically ascertained patients in either The Netherlands [6] or in literature.

Maximum percentage of weight loss was calculated as the ratio between the birth weight and the lowest weight observed in the first neonatal period.

\section{Enzyme analysis}

Residual MCAD enzyme activity was determined in leukocytes. Before 2007, a GC-MS based analysis using C6-CoA +/- butyryl-CoA (C4-CoA) as substrates was the standard in our centre $[7,8]$. The assay with $\mathrm{C} 6-\mathrm{CoA}$ has been described extensively, and was modified for more accurate analysis of MCAD enzyme activity and elimination of the contribution of short-chain acyl-CoA dehydrogenase (SCAD; OMIM 606885). In this assay 785.7 $\mu \mathrm{M}$ C4-CoA was added as a substrate, besides C6CoA. At least one commercially available leukocyte pellet (Sanquin, The Netherlands) was used as control in each enzyme assay. Molecular analysis of the ACADM gene was performed in all subjects with residual MCAD activity $<50 \%$ when determined with C6-CoA. Since 2007, an HPLC-based assay using 3-phenylpropionyl-CoA (PP-CoA) as a substrate is used [5,9]. Residual enzyme activities are expressed as a percentage from healthy controls.

\section{Clinical fasting tolerance tests}

All clinical fasting tolerance tests were performed in the clinical function test ward of the Beatrix Children's Hospital, UMC Groningen, according to established protocols $[10,11]$. Hypoglycemia was defined as blood glucose concentrations $<2.6 \mathrm{mmol} / \mathrm{l}$ [12]. The fasting tolerance test was combined with a 3-phenylpropionic acid (PPA) loading test, where $25 \mathrm{mg} / \mathrm{kg}$ PPA was administered orally [13]. Two portions of urine were collected du- 
Table 1 Characteristics of subjects with variant ACADM genotypes during fasting tolerance tests and PPA loading tests

RESULTS FASTING TEST AND PPA LOADING TEST IN CHILDREN WITH VARIANT ACADM GENOTYPES

\begin{tabular}{|c|c|c|c|c|c|c|c|c|c|c|c|c|c|c|c|c|c|}
\hline \multirow[t]{2}{*}{ Case } & \multicolumn{2}{|c|}{ Genotype } & \multicolumn{2}{|c|}{ NBS } & \multirow[b]{2}{*}{ Organic acids } & \multicolumn{3}{|c|}{ MCAD activity (\%) } & \multicolumn{8}{|c|}{ Fasting test } & \multirow{2}{*}{$\begin{array}{l}\text { PPA loading test } \\
\text { PP-glycine }\end{array}$} \\
\hline & Allele 1 & Allele 2 & C8:0 & $\begin{array}{l}\text { C8:0/ } \\
\text { C10:0 }\end{array}$ & & $\begin{array}{l}\mathrm{C6}- \\
\mathrm{CoA}\end{array}$ & $\begin{array}{l}+\mathrm{C} 4- \\
\mathrm{CoA}\end{array}$ & $\begin{array}{l}\text { PP- } \\
\text { CoA }\end{array}$ & $\begin{array}{l}\text { Age } \\
\text { (mo) }\end{array}$ & $\begin{array}{l}\text { Duration } \\
\text { (h) }\end{array}$ & $\begin{array}{c}\text { Glc } \\
(t=15 \mathrm{~h})\end{array}$ & $\begin{array}{c}\mathrm{KB} \\
(\mathrm{t}=15 \mathrm{~h})\end{array}$ & $\begin{array}{c}\text { Glc*KB } \\
(t=15 h)\end{array}$ & $\begin{array}{l}\text { FFA/KB } \\
(t=15 \mathrm{~h})\end{array}$ & $\begin{array}{c}C 8: 0 \\
(t=15 h)\end{array}$ & $\begin{array}{l}\text { C8:0/ } \\
\text { C10:0 }\end{array}$ & \\
\hline 1 & $c .985 A>G$ & c.199T>C & 2.85 & 2.3 & Normal & 39 & 36 & - & - & - & - & - & - & - & - & - & - \\
\hline 2 & c. $.985 \mathrm{~A}>\mathrm{G}$ & c.199T>C & 0.67 & 2.7 & $\mathrm{DC}, \mathrm{HG}$ & 44 & 29 & 58 & - & - & - & - & - & - & - & - & - \\
\hline 3 & c. $985 A>G$ & C.199T>C & 0.35 & 2.3 & $\begin{array}{c}\text { Trace N-HG, SG, } \\
\text { DC }\end{array}$ & 48 & 43 & 48 & - & - & - & - & - & - & - & - & - \\
\hline 4 & $c .985 \mathrm{~A}>\mathrm{G}$ & c.199T>C & 0.74 & 2.8 & Trace HG & 36 & 34 & 44 & 10 & 18 & 4.5 & 1.1 & 5.0 & 1.0 & 3.7 & 3.4 & Trace \\
\hline 5 & c. $985 A>G$ & c. $473 \mathrm{~A}>\mathrm{G}$ & 0.39 & 2.3 & Normal & 38 & 25 & 39 & 6 & 18.5 & 2.8 & 0.3 & 0.8 & 2.2 & 2.0 & 3.8 & Absent \\
\hline 6 & c. $985 \mathrm{~A}>\mathrm{G}$ & $c .734 C>T$ & 1.41 & 3.0 & $\begin{array}{c}\text { Trace DC, 5-OH-C, } \\
\text { HG, SG }\end{array}$ & 41 & 17 & 11 & 13 & 17 & 4.4 & 0.8 & 3.3 & 1.9 & 3.6 & 4.2 & Trace \\
\hline 7 & c. $985 \mathrm{~A}>\mathrm{G}$ & c. $928 \mathrm{G}>\mathrm{A}$ & 2.28 & 3.2 & 5-OH-H, trace $\mathrm{HG}$ & 48 & 23 & 0 & 16 & 15 & 3.2 & 3.5 & 10.6 & - & 1.9 & 2.9 & Absent \\
\hline 8 & c. $985 A>G$ & $\begin{array}{l}\text { Not } \\
\text { found }\end{array}$ & 0.70 & 1.3 & Normal & 28 & - & - & 25 & 18.5 & 4.0 & 0.9 & 3.7 & 1.5 & 2.9 & 2.1 & Trace \\
\hline 9 & c. $985 A>G$ & $\begin{array}{l}\text { Not } \\
\text { found }\end{array}$ & 0.50 & 0.8 & Normal & 15 & 11 & 86 & 27 & 16.5 & 2.9 & 1.4 & 5.8 & 0.8 & 0.5 & 2.2 & Trace \\
\hline * & $\begin{array}{r}\text { Classical } \\
\text { genot }\end{array}$ & $\begin{array}{l}\text { ACADM } \\
\text { type }\end{array}$ & 2.98 & 12.7 & $\begin{array}{c}\text { 5-OH-H, HG, PPG, } \\
\text { SG, DC }\end{array}$ & 28 & 14 & 0 & - & $17-24$ & 3.1 & 0.6 & 5.7 & 2.2 & - & - & High \\
\hline$\#$ & Control po & opulation & - & - & - & - & - & - & $0-24$ & 15 & $\begin{array}{c}4.1 \\
(3.1-4.8)\end{array}$ & $\begin{array}{c}1.3 \\
(0.4-3.2)\end{array}$ & $\begin{array}{c}5.5 \\
(1.2-15.4)\end{array}$ & $\begin{array}{c}1.1 \\
(0.7-2.4)\end{array}$ & - & - & Absent \\
\hline$\#$ & Control po & opulation & - & - & - & - & - & - & $25-84$ & 15 & $\begin{array}{c}4.6 \\
(3.8-5.3)\end{array}$ & $\begin{array}{c}0.5 \\
(0.1-1.7)\end{array}$ & $\begin{array}{c}2.1 \\
(0.4-8.9)\end{array}$ & $\begin{array}{c}1.8 \\
(0.8-6.4)\end{array}$ & - & - & Absent \\
\hline
\end{tabular}


ring the fasting tolerance test. Portion 1 was obtained after overnight fasting in the first 4 hours following PPA loading; the second portion was obtained in the following 4 hours of the fasting tolerance test. All PPA loading tests were performed after the age of 6 months [14]. Urinary phenylpropionylglycine was determined by gaschromatography-mass spectrometry (GC-MS), according to Chalmers et al. [15].

\section{Data analysis}

Clinical and laboratory data, and data from functional tests were retrospectively retrieved from the medical charts and laboratory files of the subjects by one investigator (CT).

Differences between normally distributed continuous data were analysed using parametric tests. Data that were not normally distributed were analysed using nonparametric tests. For analysis of correlations, Spearman's rank test was used. The significance level was set at $\mathrm{p}<0.05$. Statistical analyses were performed using GraphPad Prism software (GraphPad Software Inc., version 5.00, 2007).

\section{Results}

\section{Cohort}

From the birth cohort 2003-2011, 50 newborns were diagnosed with MCAD deficiency in our centre after referral for a positive NBS (in either the pilot screening program, or the regular nationwide NBS). In 9 of these 50 subjects $(18 \%)$ a variant $A C A D M$ genotype was identified (Table 1). In two of these subjects (cases $8 \& 9$ ), only one $A C A D M$ mutation was detected after sequencing of all exons and adjacent introns. However, acylcarnitine profiles in these subjects were indicative of MCAD deficiency, and residual MCAD enzyme activities were $<50 \%$ when measured with $\mathrm{C} 6-\mathrm{CoA}$.

Two subjects (cases 3 \& 5) were diagnosed with C8:0 concentrations below $0.50 \mu \mathrm{mol} / \mathrm{l}$. Case 3 was the younger sister of case 2, carrying the c.985A $>$ G/c.199T $>C$ $A C A D M$ genotype. Case 5 was identified during the pilot screening program. Maximum percentage of weight loss in the neonatal phase in our cohort of subjects with variant $A C A D M$ genotypes correlated with C8:0 concentrations upon NBS (Spearman $\mathrm{r}-0.89, \mathrm{p}<0.05$; median 5.9\%; range 4.7-9.8\%). In cases 3 and 5 the maximum percentage of weight loss was respectively $4.7 \%$ and $5.7 \%$; in cases 8 and 9 with only one identified $A C A D M$ mutation it was respectively $7.0 \%$ and $5.9 \%$. None of the subjects with a variant $A C A D M$ genotype presented clinically with hypoketotic hypoglycemia, either in the neonatal period or after diagnosis.

\section{In vitro studies - residual MCAD enzyme activities}

Results from in vitro analyses in the 9 subjects with variant $A C A D M$ genotypes are depicted in Table 1 and
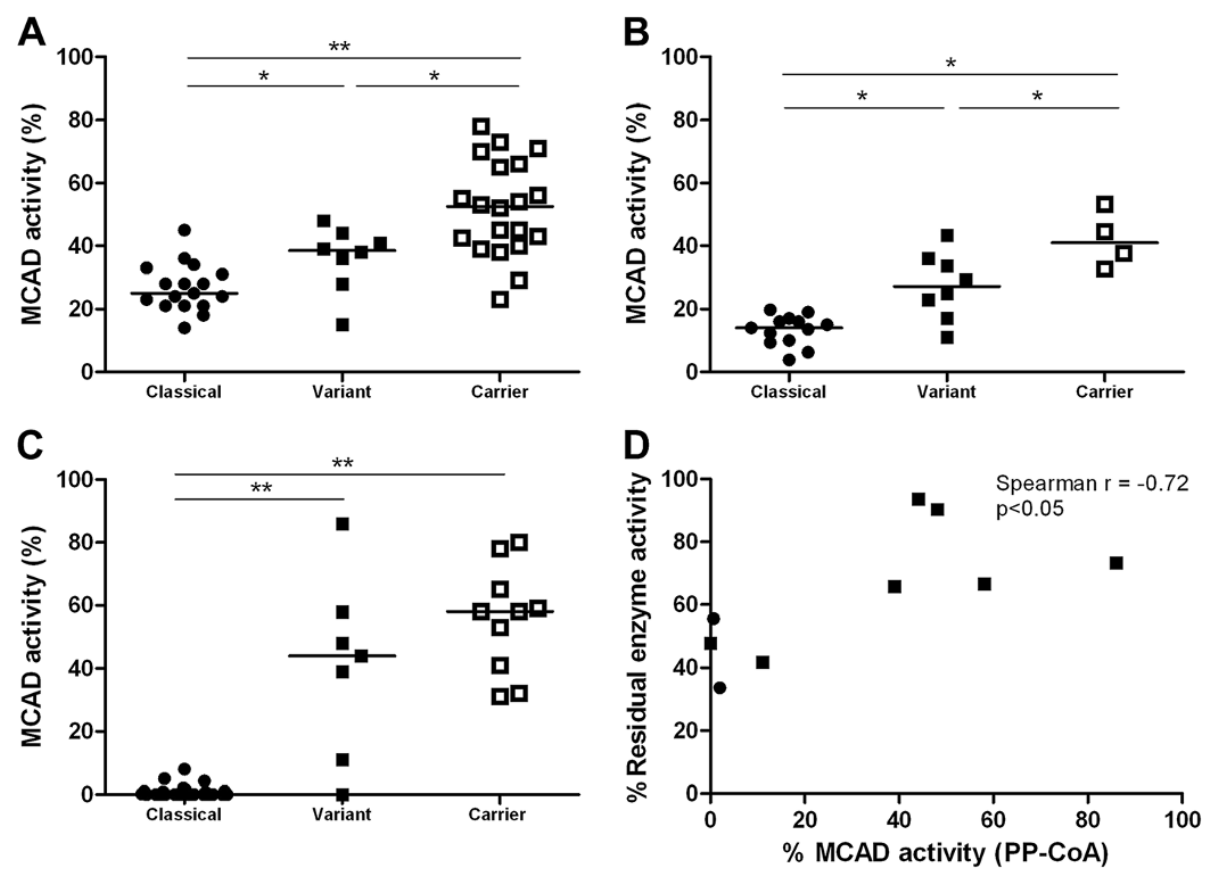

Figure 1 Residual MCAD enzyme activities measured with different substrates in leukocytes. A: Residual MCAD enzyme activities measured with C6-CoA; B: Residual MCAD enzyme activities measured with C6-CoA+C4-CoA; C: Residual MCAD enzyme activities measured with PP-CoA; D: MCAD enzyme activity with PP-CoA correlates with the effect of C4-CoA on C6-CoA enzyme activity. Enzyme activity measured with C6-CoA is set at $100 \%$ on the $y$-axis. Residual MCAD enzyme activities are depicted as percentage from controls. At least one control was included in each enzyme assay. Medians are indicated. ${ }^{*} p<0.05 ;{ }^{* *} p<0.001$. 

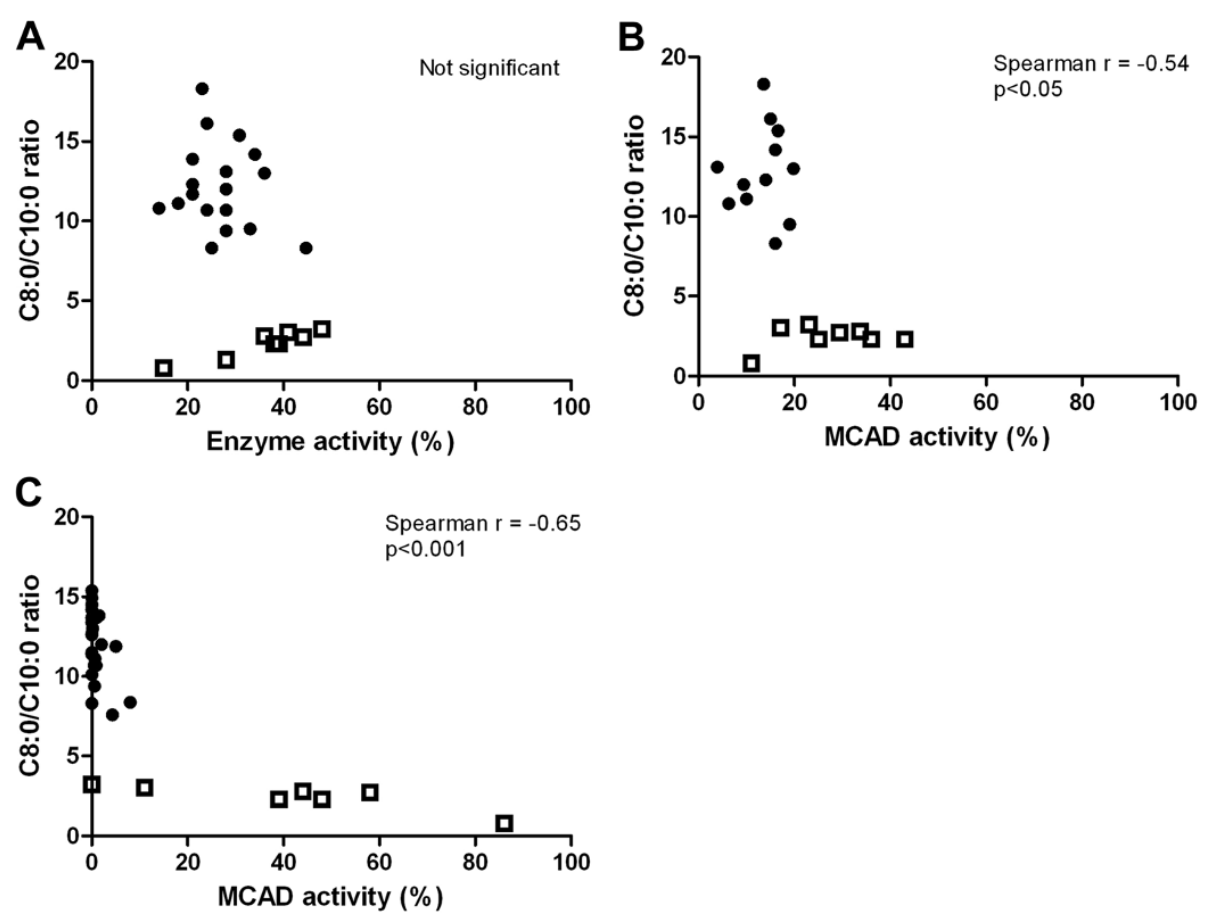

Figure 2 Correlation between residual MCAD enzyme activities measured in leukocytes and C8:0/C10:0 upon NBS. A: Residual MCAD enzyme activities measured with C6-CoA; B: Residual MCAD enzyme activities measured with C6-CoA+C4-CoA; C: Residual MCAD enzyme activities measured with PP-COA. Residual MCAD enzyme activities are depicted as percentage of controls. At least one control was included in each enzyme assay. Variant ACADM genotypes are depicted as squares, classical ACADM genotypes as dots.

Figure 1. In 7 of these subjects MCAD enzyme analyses were performed in leukocytes with three different substrates: C6-CoA, C6-CoA + C4-CoA, and PP-CoA. Irrespective of the substrate, significantly higher residual MCAD enzyme activities were measured in subjects with variant $A C A D M$ genotypes, when compared to patients with classical $A C A D M$ genotypes (Figure 1). However, when measured with PP-CoA, case 7 demonstrated no residual MCAD enzyme activity. With the natural substrates C6-CoA and C6-CoA + C4-CoA, the group of subjects with variant $A C A D M$ genotypes differed clearly from both the group with classical $A C A D M$ genotypes, and from carriers of the c.985A $>\mathrm{G}$ mutation (i.e. siblings or parents of patients). The observed proportional change in enzyme activity after addition of C4-CoA to the C6$\mathrm{CoA}$ assay correlated with the MCAD enzyme activity measured with PP-CoA (Spearman $\mathrm{r}-0.72, \mathrm{p}<0.05$ ) (Figure 1D). Additionally, strong correlations were identified between residual MCAD enzyme activities measured with PP-CoA and C6-CoA + C4-CoA, and the C8:0/C10:0 ratio identified upon NBS (Spearman $\mathrm{r}-0.65 ; \mathrm{p}<0.001$ and Spearman $\mathrm{r}-0.54 ; \mathrm{p}<0.01$, respectively) (Figure 2).

\section{In vivo studies - fasting tolerance test}

Clinical fasting tolerance tests were performed in 6 subjects with a variant $A C A D M$ genotype, at a median age of 14.5 months (range 6-27 months). The duration of fasting was supra-physiological in all subjects, as regular overnight fasting duration was extended. Case 7 fasted for 15 hours and the remaining 5 subjects for 16.5 18.5 hours (Table 1). Concentrations of glucose, free fatty acids (FFA), ketone bodies (KB), and their ratios after 15 hours of fasting are depicted in Table 1. All subjects could complete the fasting tolerance tests without clinical symptoms and/or hypoglycaemia.

Case 5 demonstrated normal fasting parameters after overnight fasting but hypoketosis after 18.5 hours. Low

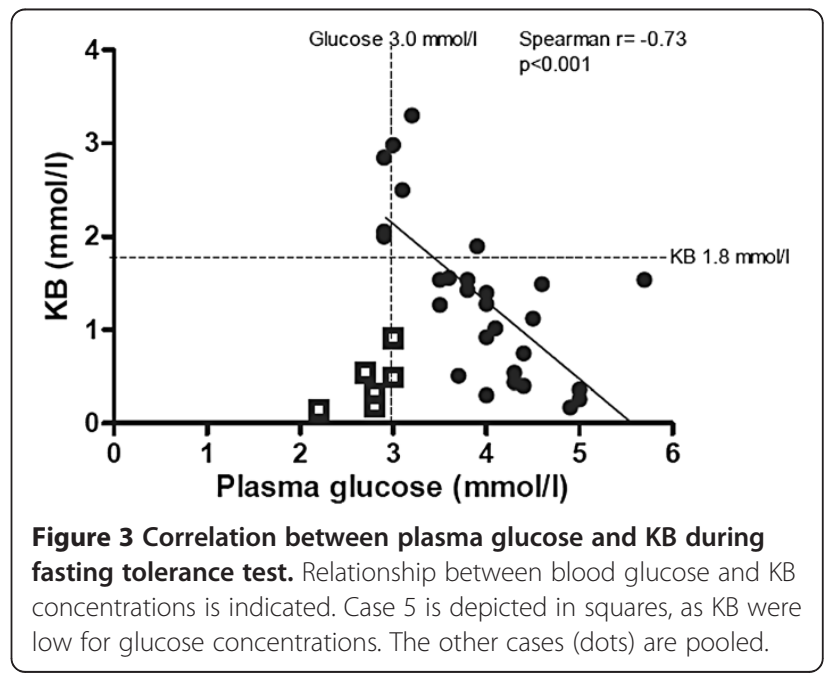


FFA concentrations that were not clearly increasing in time reflected a minimal role of mFAO under these circumstances in this subject, with subsequent low concentrations of KB (squares in Figure 3) [10,11].

Case 7 and case 9 also showed blood glucose concentrations that were below p10 for age and duration of fasting after 15 hours of fasting. FFA/KB ratios were at p10 for age and duration of fasting, with increasing concentrations of FFA and KB around p90. All other included subjects had $\mathrm{KB}$ concentrations that corresponded to blood glucose concentrations upon fasting (dots in Figure 3C).

A relationship between biochemical response to fasting and residual MCAD enzyme activity with either substrate could not be identified.

During fasting, C8:0 concentrations increased in time. Additionally, observed concentrations during fasting were considerably higher when compared to the concentrations that were seen during regular visits to the outpatient clinic (median during follow-up $0.6 \mathrm{umol} / \mathrm{l}$; median after $15 \mathrm{~h}$ fasting $3.2 \mathrm{umol} / \mathrm{l}, \mathrm{p}=0.07)$. C8:0 concentrations during fasting did not correlate with concentrations found in the initial NBS test.

The $\mathrm{C} 8: 0 / \mathrm{C} 2: 0$ and $\mathrm{C} 8: 0 / \mathrm{C} 10: 0$ ratios during fasting were slightly higher than the ratios that were identified upon NBS and during regular visits to the outpatient clinic (Table 1). During the fasting tolerance test the ratios remained stable in time in all subjects [16].

In case 8 , longer-chain acylcarnitines accumulated in time, besides medium-chain acylcarnitines (acylcarnitines after 18.5 hours of fasting: C12:0 $0.60 \mu \mathrm{mol} / \mathrm{l}, \mathrm{C} 14: 00.23$ $\mu \mathrm{mol} / \mathrm{l}, \mathrm{C} 14: 10.75 \mu \mathrm{mol} / \mathrm{l})$.

Prolonged fasting was associated with increasingly abnormal excretion patterns of organic acids, with $N$ hexanoylglycine, and dicarboxylic acids in the urine of all subjects with variant $A C A D M$ genotypes during fasting, as opposed to the observations during regular visits to the outpatient clinic, when few or no abnormal metabolites were be detected.

\section{PPA loading test}

The fasting tests were combined with a PPA loading test. After oral administration of PPA, no phenylpropionylglycine (PP-glycine) or trace amounts were excreted in the urine, together with large amounts of hippuric acid.

\section{Discussion}

Since the introduction of NBS for MCAD deficiency, a new subgroup of newborns has been identified with variant $A C A D M$ genotypes that have not been seen before in clinically ascertained patients with classical $A C A D M$ genotypes. It remains unclear whether subjects with these variant $A C A D M$ genotypes are at risk for the development of a clinical phenotype. Prevention of prolonged fasting was found to be debatable when
MCAD enzyme activities $>10 \%$ were measured with PPCoA [2]. In the current study, additional support was provided to abandon the advice on prevention of prolonged fasting under normal conditions in subjects with residual MCAD enzyme activities $>10 \%$. All included subjects could tolerate an overnight controlled fasting tolerance test for at least 15 hours under healthy conditions. An additional PPA loading test determined in vivo residual MCAD enzyme activity. These functional tests were performed after the age of 6 months in all cases, when weaning naturally occurs and PPA loading tests can be performed reliably [14].

Several factors cause diversity between the subjects with variant $A C A D M$ genotypes that have been identified since introduction of NBS. Firstly, different $A C A D M$ genotypes are represented in this group. Secondly, the NBS protocol has been adapted in 2007, and has thus not been similar for all included subjects. Thirdly, treatment in the newborn period has not been the same in all subjects in this group. Identification of affected newborn siblings of probands was associated with dietary interventions from birth onwards in this group, instead of starting after positive NBS results.

Interestingly, two cases (case 3 and case 5) were identified upon NBS with C8:0 concentrations below the current cut-off concentration of $0.50 \mu \mathrm{mol} / \mathrm{l}$, despite ACADM mutations on both alleles. Case 3 was identified upon family screening and case 5 during the pilot NBS program. With the elevation of the C8:0 cut-off concentration in 2007, the national criteria for subjects who should be regarded "patients" have also been adapted. However, due to family screening we still identify subjects with ACADM mutations on both alleles, but C8:0 concentrations below the cut-off value. How can we interpret these observations? C8:0 concentrations in newborns can theoretically be influenced by nutritional state [5], prematurity and/or very low birth weight [17], heterozygosity for the c.985A $>$ G mutation [18], and the time at which NBS is performed [19]. In our cohort, nutritional state can have affected NBS C8:0 concentrations, as these concentrations clearly correlated with percentage of maximum weight loss in the neonatal phase. Except for case 3, all subjects with a variant $A C A D M$ genotype in our cohort were firstborns who were breastfed. With breastfeeding caloric intake cannot be monitored, as opposed to during formula feeding. Especially in firstborns onset of lactation can be delayed, leading to suboptimal food intake in the first days of life [20]. Catabolism and subsequent increase in C8:0 concentrations can result from this. In case 3, C8:0 concentrations may have remained $<0.50 \mu \mathrm{mol} / \mathrm{l}$ due to the positive family history and subsequent frequent feeding regimen that was started at birth.

Two subjects in our study (case 8 and case 9) displayed only one $A C A D M$ mutation after sequencing 
of the $A C A D M$ gene. Why have these subjects been identified upon NBS, as heterozygotes are usually not identified with the current C8:0 cut-off concentration [18]? Case 8 and case 9 were not considered normal false-positives, and where included in the cohort based on the combination of (1) persisting abnormal plasma and urinary metabolites, and (2) residual MCAD enzyme activity determined with C6-CoA. Results from fasting tolerance tests were remarkable in both subjects. In case 8, acylcarnitines with increasing chain-lengths up to C16:0 accumulated upon fasting. The C8:0 concentration increased considerably to a maximum of $4.7 \mu \mathrm{mol} / \mathrm{l}$, whereas the C8:0/C10:0 remained $<2.5$. Theoretically, these findings may indicate another phenotypemodifying mutation on a gene that plays a role in mFAO, a phenomenon known as synergistic heterozygosity [21,22]. Vockley et al. described the concept of synergistic heterozygosity, i.e. multiple partial defects in more than one metabolic pathway, leading to clinical symptoms that correlate with the affected pathways [22]. In combination with the classical c.985A $>\mathrm{G} A C A D M$ mutation, theoretical candidate genes to cause accumulation of acylcarnitines with medium and long chainlength are ETFA (HGNC:3481), ETFB (HGNC:3482), ETFDH (HGNC:3483), ACADS (HGNC:90) or ACADVL (HGNC:92) especially during episodes with increased catabolic stress such as during prolonged fasting. In case 8, C14:1 concentrations increased to a maximum of $0.75 \mu \mathrm{mol} / \mathrm{l}$ upon prolonged fasting, with a corresponding $\mathrm{C} 14: 1 / \mathrm{C} 16: 0$ ratio of 4.4 . The interpretation of these findings is complicated as, currently, no paediatric reference values for acylcarnitines during prolonged fasting are available. In case 9, the in vivo and in vitro observations might be explained by other molecular mechanisms (e.g. deep-intronic mutations, mutations in the promoter region, and deletion/duplication mutations) that can be missed upon gene sequencing, next to synergistic heterozygosity [23,24].

We observed a normal fasting tolerance in subjects with variant $A C A D M$ genotypes and residual MCAD enzyme activities $>10 \%$ under normal conditions after the age of 6 months. Based on these results, the need to prescribe a standard late evening meal in these subjects is debatable. PPA loading tests cannot be reliably performed before the age of 6 months [14]. As PPA loading tests were in this study combined with the fasting tolerance tests, no data are currently available on fasting tolerance in subjects with variant $A C A D M$ genotypes and residual MCAD enzyme activities $>10 \%$ before the age of 6 months. It is well known that even patients with classical $A C A D M$ genotypes can tolerate overnight fasting already at a young age $[6,25]$. Besides, stable isotope studies demonstrated normal FFA and KB metabolism in patients with classical $A C A D M$ genotypes [26,27].
Administration of a late evening meal has several disadvantages: First of all, it can be considered a burden for both parents and the child, especially in the first year of life when the maximum duration of fasting is 6-8 hours [28]. Additionally, administration of a late evening meal increases the risks on overfeeding and dental caries $[6,29]$. In our opinion, abovementioned arguments, combined with the current data, justify abolishing a standard late evening meal in subjects with variant $A C A D M$ genotypes and residual MCAD enzyme activities $>10 \%$ after the age of 6 months. In vivo functional tests can facilitate development of individualized patient-based guidelines for follow-up reliably from the age of 6 months. However, until the pathophysiology of MCAD deficiency and its variants is unravelled, an emergency regimen and parental instructions remain indispensable in the follow-up of all subjects with a positive NBS for MCAD deficiency.

\section{Conclusions}

Variant $A C A D M$ genotypes with residual MCAD enzyme activities $>10 \%$ in vitro are associated with normal residual MCAD enzyme activities in vivo (defined by PPA loading) and normal fasting tolerance. The general advice to prevent prolonged fasting can be abolished in subjects with residual MCAD enzyme activities $>10 \%$ after the age of 6 months. However, an emergency regimen and parental instructions remain necessary in all subjects with MCAD deficiency, regardless of residual MCAD enzyme activity, at least until the pathophysiology of MCAD deficiency has been elucidated.

\section{Abbreviations \\ ACADM: Gene encoding medium-chain acyl-CoA dehydrogenase; ACADVL: Gene encoding very long-chain acyl-CoA dehydrogenase; C2:0: Acetylcarnitine; C4-CoA: Butyryl-CoA; C6-CoA: Hexanoyl-CoA; ETF: Electron transfer flavoprotein; C8:0: Octanoylcarnitine; C10:0: Decanoylcarnitine; C10:1: Decenoylcarnitine; \\ C14:1: Tetradecenoylcarnitine; C16:0: Palmitoylcarnitine; C8:0/C2:0: Ratio between octanoylcarntine and acetylcarnitine; C8:0/C10:0: Ratio between octanoylcarnitine and decanoylcarnitine; FFA: Free fatty acids; KB: Ketone bodies; MCAD: Medium-chain acy-CoA dehydrogenase; mFAO: Mitochondrial fatty acid oxidation; NBS: Newborn bloodspot screening; PPA: Phenylpropionic acid; PP-CoA: Phenylpropionyl-CoA; PP- Glycine: Phenylpropionylglycine.}

\section{Competing interests}

The authors declare that they have no competing interest.

\section{Authors' contributions}

CML Touw participated in data collection, analysis and interpretation, generation of the figures, in writing of the manuscript, and approved of the final version. KE Niezen-Koning participated in data collection, and approved of the final version. C Bosgraaf-de Boer participated in laboratory analyses and data collection, and approved of the final version. A Gerding participated in laboratory analyses and data collection, and approved of the final version. GPA Smit, DJ Reijngoud and TGJ Derks conceived the study, participated in writing the manuscript, and approved of the final version.

\section{Acknowledgements}

This study was funded by a grant from Health Insurers Innovation Foundation to DJ Reijngoud and GPA Smit (project number 913). The funding source had no role in the writing of the manuscript, but was 
informed about the decision to submit the manuscript for publication. No authors were paid by a pharmaceutical company or other agency to write this article.

The authors would like to thank Jouktje Bonnema for her aid with the fasting tolerance tests and phenylpropionic acid loading tests.

\section{Author details}

${ }^{1}$ Section of Metabolic Diseases, Beatrix Children's Hospital, University of Groningen, University Medical Centre, Groningen, The Netherlands. ${ }^{2}$ Laboratory of Metabolic Diseases, Department of Laboratory Medicine, University of Groningen, University Medical Centre, Groningen, The Netherlands. ${ }^{3}$ Center for Liver, Digestive and Metabolic Diseases, University of Groningen, University Medical Centre of Groningen, PO Box 30 001CA84, Groningen 9700 RB, The Netherlands.

Received: 20 February 2013 Accepted: 17 March 2013

Published: 20 March 2013

\section{References}

1. Roe CR, Ding J: Chapter 101: Mitochondrial fatty acid oxidation disorders. In In The online metabolic and molecular bases of inherited disease. 8th edition. Edited by Valle D, Scriver CR. New York: McGraw-Hill; 2001.

2. Touw CM, Smit GP, de Vries M, de Klerk JB, Bosch AM, Visser G, Mulder MF, Rubio-Gozalbo ME, Elvers B, Niezen-Koning KE, Wanders RJ, Waterham HR, Reijngoud DJ, Derks TG: Risk stratification by residual enzyme activity after newborn screening for medium-chain acyl-CoA dehyrogenase deficiency: Data from a cohort study. Orphanet J Rare Dis 2012, 7(1):30.

3. Sturm M, Herebian D, Mueller M, Laryea MD, Spiekerkoetter U: Functional effects of different medium-chain acyl-coa dehydrogenase genotypes and identification of asymptomatic variants. PLoS One 2012, 7(9):e45110.

4. Zschocke J, Schulze A, Lindner M, Fiesel S, Olgemoller K, Hoffmann GF, Penzien J, Ruiter JP, Wanders RJ, Mayatepek E: Molecular and functional characterisation of mild MCAD deficiency. Hum Genet 2001, 108(5):404-408.

5. Derks TG, Boer TS, van Assen A, Bos T, Ruiter J, Waterham HR, NiezenKoning KE, Wanders RJ, Rondeel JM, Loeber JG, Ten Kate LP, Smit GP, Reijngoud DJ: Neonatal screening for medium-chain acyl-CoA dehydrogenase (MCAD) deficiency in The Netherlands: the importance of enzyme analysis to ascertain true MCAD deficiency. J Inherit Metab Dis 2008, 31(1):88-96.

6. Derks TG, Reijngoud DJ, Waterham HR, Gerver WJ, van den Berg MP, Sauer PJ, Smit GP: The natural history of medium-chain acyl CoA dehydrogenase deficiency in the Netherlands: clinical presentation and outcome. J Pediatr 2006, 148(5):665-670.

7. Niezen-Koning KE, Chapman TE, Mulder IE, Smit GP, Reijngoud DJ, Berger R: Determination of medium chain acyl-CoA dehydrogenase activity in cultured skin fibroblasts using mass spectrometry. Clin Chim Acta 1991, 199(2):173-184.

8. Niezen-Koning KE, Wanders RJ, Nagel GT, Sewell AC, Heymans HS: Measurement of short-chain acyl-CoA dehydrogenase (SCAD) in cultured skin fibroblasts with hexanoyl-CoA as a competitive inhibitor to eliminate the contribution of medium-chain acyl-CoA dehydrogenase. Clin Chim Acta 1994, 229(1-2):99-106.

9. Wanders RJ, Ruiter JP, IJLst L, Waterham HR, Houten SM: The enzymology of mitochondrial fatty acid beta-oxidation and its application to followup analysis of positive neonatal screening results. J Inherit Metab Dis 2010, 33(5):479-494.

10. Bonnefont JP, Specola NB, Vassault A, Lombes A, Ogier H, de Klerk JB, Munnich A, Coude M, Paturneau-Jouas M, Saudubray JM: The fasting test in paediatrics: application to the diagnosis of pathological hypo- and hyperketotic states. Eur J Pediatr 1990, 150(2):80-85.

11. van Veen MR, van Hasselt PM, de Sain-van der Velden MG, Verhoeven N, Hofstede FC, de Koning TJ, Visser G: Metabolic profiles in children during fasting. Pediatrics 2011, 127(4):e1021-e1027.

12. Koh TH, Aynsley-Green A, Tarbit M, Eyre JA: Neural dysfunction during hypoglycaemia. Arch Dis Child 1988, 63(11):1353-1358.

13. Rumsby G, Seakins JW, Leonard JV: A simple screening test for mediumchain acyl CoA dehydrogenase deficiency. Lancet 1986, 2(8504):467.

14. Bennett MJ, Bhala A, Poirier SF, Ragni MC, Willi SM, Hale DE: When do gut flora in the newborn produce 3-phenylpropionic acid? Implications for early diagnosis of medium-chain acyl-CoA dehydrogenase deficiency. Clin Chem 1992, 38(2):278-281.
15. Chalmers RA, Watts RW, Lawson AM: A comprehensive screening method for detecting organic acidurias and other metabolic diseases in acutely sick infants and children. Ann Clin Biochem 1977, 14(3):149-156.

16. McHugh DM, Cameron CA, Abdenur JE, Abdulrahman M, Adair O, Al Nuaimi SA, Ahlman H, Allen JJ, Antonozzi I, Archer S, Au S, Auray-Blais C, Baker M, Bamforth F, Beckmann K, Pino GB, Berberich SL, Binard R, Boemer F, Bonham J, Breen NN, Bryant SC, Caggana M, Caldwell SG, Camilot M, Campbell C, Carducci C, Bryant SC, Caggana M, Caldwell SG, et al: Clinical validation of cutoff target ranges in newborn screening of metabolic disorders by tandem mass spectrometry: a worldwide collaborative project. Genet Med 2011, 13(3):230-254.

17. Pourfarzam M, Morris A, Appleton M, Craft A, Bartlett K: Neonatal screening for medium-chain acyl-CoA dehydrogenase deficiency. Lancet 2001, 358(9287):1063-1064.

18. Blois B, Riddell C, Dooley K, Dyack S: Newborns with C8-acylcarnitine level over the 90th centile have an increased frequency of the common MCAD 985A > G mutation. J Inherit Metab Dis 2005, 28(4):551-556.

19. Chace DH, Hillman SL, Van Hove JL, Naylor EW: Rapid diagnosis of MCAD deficiency: quantitative analysis of octanoylcarnitine and other acylcarnitines in newborn blood spots by tandem mass spectrometry. Clin Chem 1997, 43(11):2106-2113.

20. Dewey KG, Nommsen-Rivers LA, Heinig MJ, Cohen RJ: Risk factors for suboptimal infant breastfeeding behavior, delayed onset of lactation, and excess neonatal weight loss. Pediatrics 2003, 112(3 Pt 1):607-619.

21. Schuler AM, Gower BA, Matern D, Rinaldo P, Vockley J, Wood PA: Synergistic heterozygosity in mice with inherited enzyme deficiencies of mitochondrial fatty acid beta-oxidation. Mol Genet Metab 2005, 85(1):7-11.

22. Vockley J, Rinaldo P, Bennett MJ, Matern D, Vladutiu GD: Synergistic heterozygosity: disease resulting from multiple partial defects in one or more metabolic pathways. Mol Genet Metab 2000, 71(1-2):10-18.

23. El-Maarri O, Herbiniaux U, Graw J, Schroder J, Terzic A, Watzka M, Brackmann HH, Schramm W, Hanfland P, Schwaab R, Muller CR, Oldenburg $\mathrm{J}$ : Analysis of mRNA in hemophilia A patients with undetectable mutations reveals normal splicing in the factor VIII gene. J Thromb Haemost 2005, 3(2):332-339.

24. Tanner AK, Chin EL, Duffner PK, Hegde M: Array CGH improves detection of mutations in the GALC gene associated with Krabbe disease. Orphanet J Rare Dis 2012, 7:38. 1172-7-38.

25. Walter $\mathrm{JH}$ : Tolerance to fast: rational and practical evaluation in children with hypoketonaemia. J Inherit Metab Dis 2009, 32(2):214-217.

26. Fletcher JM, Pitt JJ: Fasting medium chain acyl-coenzyme $A$ dehydrogenase-deficient children can make ketones. Metabolism 2001, 50(2):161-165.

27. Heales SJ, Thompson GN, Massoud AF, Rahman S, Halliday D, Leonard JV: Production and disposal of medium-chain fatty acids in children with medium-chain acyl-CoA dehydrogenase deficiency. J Inherit Metab Dis 1994, 17(1):74-80.

28. Derks TG, van Spronsen FJ, Rake JP, van der Hilst CS, Span MM, Smit GP: Safe and unsafe duration of fasting for children with MCAD deficiency. Eur J Pediatr 2007, 166(1):5-11.

29. Meurman PK, Pienihakkinen K: Factors associated with caries increment: a longitudinal study from 18 months to 5 years of age. Caries Res 2010, 44(6):519-524.

doi:10.1186/1750-1172-8-43

Cite this article as: Touw et al.: In vitro and in vivo consequences of variant medium-chain acyl-CoA dehydrogenase genotypes. Orphanet Journal of Rare Diseases 2013 8:43. 